DOI:

УДК 621.865 .8

О.Д. Романюк, к.т.н., доцент, oleksandrromaniuk5@gmail.com

Дніпровський державний технічний університет, м. Кам'янське

\title{
ОПТИМІЗАЦІЯ СТУПІНЧАТИХ ЗУБЧАСТИХ ПЕРЕДАЧ ПО КРИТЕРІЯМ МІЦНОСТІ
}

В даній роботі розглянуто задачу проектування ступінчастих зубчастих передач ступені яких повинні задовольняти умові рівноміцності, щзо забезпечить рівномірний термін їх довговічності та рівень надійності. Введений коефіцієнт співвідночення передаточних чисел ступенів редуктора дає можливість на етапі попереднього проектування підбирати передаточні числа для відповідних ступенів редуктора таким чином, щь забезпечує умову оптимізаиіі ступінчастих зубчастих передач по критеріям міиності.

Ключові слова: редуктор; зубчасте колесо; міцність; ступінь; проектування.

This paper considers the problem of designing step gears which must satisfy the condition of uniformity, which will ensure their uniform durability and level of reliability. The introduced ratio of the gear ratios of the gearbox makes it possible at the preliminary design stage to select the gear ratios for the respective gearbox gears in such a way that provides a condition for optimizing the gears on the strength criteria.

Keywords: reducer; gear; strength; degree; design.

\section{Постановка проблеми}

Оптимізацію кінематичних та силових характеристик приводу виконавчого органу машинного агрегату вирішують різними способами, серед яких найбільш поширений полягає в використанні додаткових махових мас $[1,2,3]$, що обумовлює збільшення ваги механізму. Оптимальним вирішенням відповідного протиріччя $є$ спосіб підбору такого стандартного редуктора, маховий момент обертальних вузлів якого відповідав би додатковій маховій масі. Але на практиці підібрати відповідний редуктор практично не можливо, тому доцільніше проектувати нові, моменти інерції обертальних мас яких могли б виконувати функцію маховика, 3 обов'язковим закладанням умов рівноміцності ступенів механічної передачі.

\section{Аналіз останніх досліджень та публікацій}

Загальний підхід вирішення поставленої проблеми полягає в необхідності підбору на стадії попереднього проектування відповідних мас обертальних вузлів зубчастої передачі, яка б відповідала маховому моменту маховика. Відповідного роду задачу було вирішено в роботах $[4,5,6]$, але тільки з урахуванням маси зубчастих коліс, при тому, що значну частину маси обертальних вузлів передачі складає маса валу та його вузлів кріплення. В роботах $[7,8]$ на основі математичної моделі складальної одиниці вузла обертання механічної передачі отримано залежності, які дають можливість оцінити масу обертального елементу в першому наближені на етапі попереднього проектування, з метою стабілізації кінематичних та динамічних характеристик машинного агрегату без використання додаткових махових мас. Вирішення поставленої задачі методами, які відображені в роботах $[4,5,6,7,8]$ для багатоступінчастих редукторів призведе до збільшення габаритних розмірів, що обумовлює нерівномірний термін довговічності та рівень надійності відповідних елементів передачі. Тому доцільніше розв'язувати задачу в комплексі, тобто з обов'язковим закладанням умов рівноміцності ступенів механічної передачі на етапі попереднього проектування.

\section{Формулювання мети дослідження}

Задачі проектування ступінчастих зубчастих механізмів являються багато критеріальними, так як виникає необхідність враховувати параметри, які являються взаємно залежними. В даному випадку з однієї сторони, необхідно підібрати відповідні маси вузлів обертання механічної передачі, які б виконували роль маховика, а з іншої сторони, ступені редуктора повинні задовольняти умові рівноміцності, що забезпечить рівномірний термін довговічності та рівень 
надійності відповідних елементів передачі. Такий підхід являється найбільш економічно обгрунтованим, так як суттєво знижує витрати на виготовлення та особливо обслуговування відповідних редукторів.

В даній роботі розглянуто задачу проектування ступінчастих зубчастих передач ступені яких повинні задовольняти умові рівноміцності, що забезпечить рівномірний термін їх довговічності та рівень надійності. Тобто, згідно основного рівняння міцності

$$
\sigma_{H} \leq\left[\sigma_{H}\right],
$$

на основі відповідних перемінних величин проектування необхідно встановити залежності та взаємозв'язок між ними для спрощення задачі проектування рівноміцностних ступенів зубчастих передач. Для отримання основних закономірностей проектування зубчастих передач ступені яких задовольняють умові рівноміцності достатньо розглянути двохступінчатий редуктор.

\section{Виклад основного матеріалу}

Базова математична модель двохступінчатого редуктора, який є елементом моделі машинного агрегату, для вирішення поставленої задачі проектування рівноміцностних ступенів зубчастих передач представлена на рис. 1 .

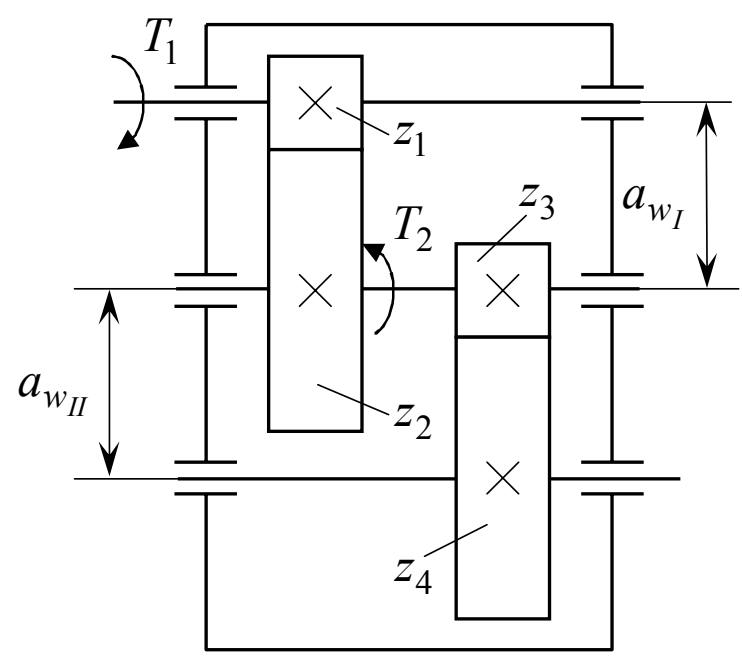

Рис. 1. Математична модель двохступінчатого редуктора

Елементами даної моделі є вузли обертання зубчастої передачі, які характеризуються наступними основними параметрами: $T$ - обертальний момент, $\mathrm{H} \times \mathrm{M} ; Z-$ число зубів зубчастого колеса; $a_{w_{I}}$ - міжосьова відстань першої ступені, мм; $a_{w_{I I}}$ - міжосьова відстань другої ступені, мм.

Так як, основним розрахунком зубчастих передач на міцність $є$ розрахунок по контактним напруженням, то базове рівняння запишемо у наступному вигляді

$$
\sigma_{H_{i}}=1,18 \sqrt{\frac{E_{n p} T_{i} K_{H_{i}}}{b_{i} d_{i}^{2} \sin 2 \alpha}\left(\frac{u_{i j} \pm 1}{u_{i j}}\right)},
$$

де $\sigma_{H_{i}}-$ розрахункова величина контактних напружень відповідної ступені, МПа; $E_{n p}-$ приведений модуль пружності матеріалу зубчастих коліс, МПа; $T_{i}$ - обертальний момент $i$-того валу, $\mathrm{H} \times \mathrm{m} ; K_{H_{i}}$ - коефіцієнт розрахункового навантаження відповідної ступені; $b_{i}$ ширина вінця $i$-того зубчастого колеса, мм; $d_{i}$ - ділильний діаметр $i$-того зубчастого колеса, мм; $\alpha=20^{\circ}$ - кут зачеплення; $u_{i j}$ - передаточне число відповідної ступені. 
Для забезпечення рівномірного терміну довговічності та рівня надійності ступенів зубчастих передач необхідно, щоб виконувалась умова:

$$
\sigma_{H_{I}}=\sigma_{H_{I I}} \text {. }
$$

Враховуючи, що зубчасті колеса усіх ступенів редуктора виготовляють 3 одного матеріалу, а коефіцієнти розрахункового навантаження для першої та другої ступені в першому наближені практично одинакові, то приймаємо, що:

$$
\frac{E_{n p} K_{H_{i}}}{\sin 2 \alpha}=\text { const }=k .
$$

Відповідно базове рівняння приймає вигляд

$$
\sigma_{H_{i}}=1,18 \sqrt{k \frac{T_{i}}{b_{i} d_{i}^{2}}\left(\frac{u_{i j} \pm 1}{u_{i j}}\right)}=1,18 \sqrt{k} \times \sqrt{\frac{T_{i}}{b_{i} d_{i}^{2}}\left(\frac{u_{i j} \pm 1}{u_{i j}}\right)} .
$$

Таким чином, розрахункова величина контактних напружень для першої та другої ступені редуктора визначається наступними рівняннями:

$$
\begin{gathered}
\sigma_{H_{I}}=1,18 \sqrt{k} \times \sqrt{\frac{T_{1}}{b_{1} d_{1}^{2}}\left(\frac{u_{12}+1}{u_{12}}\right)} ; \\
\sigma_{H_{I I}}=1,18 \sqrt{k} \times \sqrt{\frac{T_{2}}{b_{3} d_{3}^{2}}\left(\frac{u_{34}+1}{u_{34}}\right)} .
\end{gathered}
$$

Згідно умови рівноміцності ступенів редуктора

$$
\sqrt{\frac{T_{1}}{b_{1} d_{1}^{2}}\left(\frac{u_{12}+1}{u_{12}}\right)}=\sqrt{\frac{T_{2}}{b_{3} d_{3}^{2}}\left(\frac{u_{34}+1}{u_{34}}\right)} .
$$

Враховуючи, що величина обертального моменту на проміжному валу

$$
T_{2}=T_{1} u_{12}
$$

та виконавши прості перетворення, отримаємо

$$
\frac{\left(u_{12}+1\right)}{b_{1} d_{1}^{2} u_{12}}=\frac{u_{12}\left(u_{34}+1\right)}{b_{3} d_{3}^{2} u_{34}} .
$$

Розглянемо окремо ліву та праву частини даного рівняння, 3 урахуванням, що $b=\psi_{b a} a_{w}$, де $\psi_{b a}$ - коефіцієнт ширини вінця зубчастого колеса по міжосьовій відстані,

$$
\begin{gathered}
\frac{u_{12}+1}{b_{1} d_{1}^{2} u_{12}}=\frac{1}{\psi_{b a} a_{w_{I}} d_{1}^{2}} \times \frac{u_{12}+1}{u_{12}} ; \\
\frac{u_{12}\left(u_{34}+1\right)}{b_{3} d_{3}^{2} u_{34}}=\frac{1}{\psi_{b a} a_{w_{I I}} d_{3}^{2}} \times \frac{u_{12}\left(u_{34}+1\right)}{u_{34}} .
\end{gathered}
$$

Прирівнюючи отримані залежності з урахуванням, що:

$$
\begin{gathered}
a_{w_{I}}=\frac{1}{2}\left(d_{1}+d_{2}\right)=\frac{1}{2}\left(u_{12}+1\right) z_{1} m_{I}, \text { та } d_{1}=m_{I} z_{1} ; \\
a_{w_{I I}}=\frac{1}{2}\left(d_{3}+d_{4}\right)=\frac{1}{2}\left(u_{34}+1\right) z_{3} m_{I I}, \text { та } d_{3}=m_{I I} z_{3},
\end{gathered}
$$

де $m_{I}$ та $m_{I I}$ - модулі зачеплення першої та другої ступені відповідно, $м м$, а також виконавши прості перетворення з урахуванням, що коефіцієнт ширини вінця зубчастого колеса по міжосьовій відстані однаковий для обох ступенів, отримаємо

Спростивши вираз маємо

$$
\frac{\left(u_{34}+1\right) z_{3}^{3} m_{I I}^{3}}{\left(u_{12}+1\right) z_{1}^{3} m_{I}^{3}}=\frac{u_{12}^{2}\left(u_{34}+1\right)}{u_{34}\left(u_{12}+1\right)} .
$$




$$
\frac{z_{3}^{3} m_{I I}^{3}}{z_{1}^{3} m_{I}^{3}}=\frac{u_{12}^{2}}{u_{34}} .
$$

Дане рівняння включає в собі значно меншу кількість перемінних ніж базове, але являється незручним для проведення вибору відповідних параметрів на етапі попереднього проектування ступенів редуктора, які б задовольняли умові рівноміцності. Як правило, розрахунок проводять по кожній ступені окремо, то розділимо по можливості переміні величини першої та другої ступені

$$
\frac{z_{3}^{3}}{z_{1}^{3}}=\left(\frac{m_{I}}{m_{I I}}\right)^{3} \frac{u_{12}^{2}}{u_{34}},
$$

відповідно

$$
z_{3}=z_{1}\left(\frac{m_{I}}{m_{I I}}\right) \sqrt[3]{\frac{u_{12}^{2}}{u_{34}}} .
$$

Враховуючи, що $d_{1}=m_{I} z_{1}$ i $d_{3}=m_{I I} z_{3}$, отримане рівняння можна переписати наступним чином

$$
d_{3}=d_{1} \sqrt[3]{\frac{u_{12}^{2}}{u_{34}}} .
$$

Для зручності проведення аналізу та розрахунків геометричних параметрів зубчастих коліс ступенів редуктора введемо поняття коефіцієнта співвідношення передаточних чисел ступенів редуктора $k_{u}$,

$$
k_{u}=\sqrt[3]{\frac{u_{12}^{2}}{u_{34}}} .
$$

Коефіцієнт $k_{u}$, значення якого наведені в табл. 1, дає можливість на етапі попереднього проектування підбирати передаточні числа для відповідних ступенів редуктора таким чином, що їх комбінація забезпечить умови рівноміцності зубчастих коліс.

Таблиия 1. Коефіцієнт співвідношення передаточних чисел ступенів редуктора

\begin{tabular}{|c|c|c|c|c|c|c|c|c|c|c|}
\hline & \multicolumn{10}{|c|}{$\mathbf{u}_{\mathbf{1 2}}$} \\
\hline \multirow{4}{*}{$\mathbf{u}$} & $\mathbf{1 , 0}$ & $\mathbf{1 , 2 5}$ & $\mathbf{1 , 6}$ & $\mathbf{2 , 0}$ & $\mathbf{2 , 5}$ & $\mathbf{3 , 1 5}$ & $\mathbf{4 , 0}$ & $\mathbf{5 , 0}$ & $\mathbf{6 , 3}$ \\
\cline { 2 - 12 } & $\mathbf{1 , 0}$ & 1,00 & 1,16 & 1,37 & 1,59 & 1,84 & 2,15 & 2,52 & 2,92 & 3,41 \\
\hline $\mathbf{1 , 2 5}$ & 0,93 & 1,08 & 1,27 & 1,47 & 1,71 & 1,99 & 2,34 & 2,71 & 3,08 \\
\cline { 2 - 12 } & $\mathbf{1 , 6}$ & 0,85 & 0,99 & 1,17 & 1,36 & 1,58 & 1,84 & 2,15 & 2,50 & 2,84 \\
\cline { 2 - 11 } & $\mathbf{2 , 0}$ & 0,79 & 0,92 & 1,09 & 1,26 & 1,46 & 1,71 & 2,00 & 2,32 & 2,64 \\
\cline { 2 - 11 } & $\mathbf{2 , 5}$ & 0,74 & 0,85 & 1,01 & 1,17 & 1,36 & 1,58 & 1,86 & 2,15 & 2,45 \\
\hline & $\mathbf{3 , 1 5}$ & 0,68 & 0,79 & 0,93 & 1,08 & 1,26 & 1,47 & 1,72 & 1,99 & 2,27 \\
\hline $\mathbf{4 , 0}$ & 0,63 & 0,73 & 0,86 & 1,00 & 1,16 & 1,35 & 1,59 & 1,84 & 2,09 \\
\hline $\mathbf{5 , 0}$ & 0,58 & 0,68 & 0,80 & 0,93 & 1,08 & 1,26 & 1,47 & 1,71 & 1,94 \\
\hline & $\mathbf{6 , 3}$ & 0,54 & 0,63 & 0,74 & 0,86 & 1,00 & 1,16 & 1,36 & 1,58 & 1,80 \\
\hline
\end{tabular}

Таким чином, поставлену задачу проектування ступінчастих зубчастих передач, ступені яких повинні задовольняти умові рівноміцності, що забезпечить рівномірний термін їх довговічності та рівень надійності вирішуємо згідно рівняння

$$
d_{3}=k_{u} d_{1},
$$

в якому коефіцієнт співвідношення передаточних чисел ступенів редуктора вибирається з інтервалу

$$
0,54 \leq k_{u} \leq 3,41
$$


Враховуючи вище розглянуті спрощення, які були допущені в процесі розв'язання поставленої задачі, введений коефіцієнт співвідношення передаточних чисел ступенів редуктора в загальному випадку можна розглядати, як деяку функцію параметрів, які повинні відповідати нормативним вимогам та відповідним стандартам, що використовуються в процесі проектування зубчастих коліс механічних передач.

$$
k_{u}=f\left(u_{i j}, E_{n p}, K_{H}, \psi_{b a}\right) \text {, }
$$

де $K_{H}=K_{H \alpha} \cdot K_{H \beta} \cdot K_{H v}$, відповідно: $K_{H \alpha}$ - коефіцієнт враховуючий нерівномірність розподілення навантаження між зубцями; $K_{H \beta}$ - коефіцієнт враховуючий нерівномірність розподілення навантаження по довжині зуба; $K_{H v}$ - коефіцієнт динамічності.

\section{Висновки}

На основі залежностей, які отримані на базі математичної моделі двохступінчатого редуктора розв'язана задача проектування ступінчастих зубчастих передач, ступені яких задовольняють умові рівноміцності, що забезпечить рівномірний термін їх довговічності та рівень надійності.

Згідно отриманих результатів можна стверджувати, що введений коефіцієнт співвідношення передаточних чисел ступенів редуктора дає можливість на етапі попереднього проектування підбирати передаточні числа для відповідних ступенів редуктора таким чином, що забезпечить умову оптимізації ступінчастих зубчастих передач по критеріям міцності.

Встановлено залежність коефіцієнта співвідношення передаточних чисел ступенів редуктора від нормативних вимог та відповідних стандартів, які використовуються в процесі проектування зубчастих коліс механічних передач.

\section{Список використаної літератури}

1. Геминтерн В.Н. Методы оптимального проектирования : Москва : Энергия, 1980. 160 с.

2. Соболь И.М., Статников Р.Б. Выбор оптимальных параметров в задачах со многими критериями : Москва : Дрофа, 2006. 175 с.

3. Джента Дж. Накопители кинетической енергии. Теория и практика современных маховичных систем : Москва : Мир, 1988. 430 с.

4. Романюк О.Д. Вибір махових мас ланок передаточних механізмів на основі оптимізації передаточної функції. Математичне моделювання. 2015. №2(33). С. 52-54.

5. Романюк О.Д. Оптимізація мас зубчастих коліс механічної передачі на етапі попереднього проектування. Математичне моделювання. 2016. №2(35). С. 35-38.

6. Романюк О.Д. Основні підходи оптимізації мас зубчастих коліс механічної передачі. Математичне моделювання. 2018. №1(38). С. 118-123.

7. Romaniuk A.D. Development of rotary units mechanical transmission mathematical model. Математичне моделювання. 2019. №2(41). С. 53-61.

8. Романюк О.Д. Оптимізація мас валів і підшипників механічної передачі. Математичне моделювання. 2020. №1(42). С. 41-47.

\section{OPTIMIZATION OF STEPPED GEARS BY STRENGTH CRITERIA Romaniuk O.}

\section{Abstract}

Optimization of kinematic and power characteristics of the drive of the executive body of the machine unit is solved in various ways, among which the most common is the use of additional flywheels, which causes an increase in the weight of the mechanism. The optimal solution to the corresponding contradiction is a method of selecting such a standard gearbox, the swing torque of which 
would correspond to the additional flywheel. But in practice it is almost impossible to choose a suitable gearbox, so it is better to design new ones, the moments of inertia of the rotating masses of which could perform the function of a flywheel, with mandatory conditions for the uniformity of mechanical gears.

The tasks of designing step gears are many criteria, as there is a need to take into account the parameters that are interdependent. In this case, on the one hand, it is necessary to select the appropriate mass of mechanical transmission units that would act as a flywheel, and on the other hand, the gear stage must meet the condition of uniformity, which will ensure uniform durability and reliability of the respective transmission elements. This approach is the most cost-effective, as it significantly reduces the cost of manufacturing and especially maintenance of the respective gearboxes.

This paper considers the problem of designing step gears which must satisfy the condition of uniformity, which will ensure their uniform durability and level of reliability.

Based on the dependences obtained from the mathematical model of a two-speed gearbox, the problem of designing step gears, the stages of which satisfy the condition of uniformity, is solved. According to the obtained results, it can be stated that the introduced ratio of gear ratios of the gearbox allows at the preliminary design stage to select gear ratios for the respective gearbox gears in such a way as to provide a condition for optimizing step gears by strength criteria.

\section{References}

[1] Gemintern V.N., \& Kogan B.M. (1980) Metody optimal'nogo proektirovanija.[Methods of optimal design]. Moscow: Energiia [In Russian].

[2] Sobol I.M., \& Statnikov R.B. (2006) Vybor optimal'nyh parametrov v zadachah so mnogimi kriterijami [Choosing the optimal parameters in problems with many criteria]. Moscow: Drofa [In Russian].

[3] J. Genta. (1988) Nakopiteli kineticheskoj energii. Teorija i praktika sovremennyh mahovichnyh system [Aggregators kinetic energy here. Theory and practice of advanced flywheel systems] Moscow: Mir [In Russian].

[4] Romaniuk O.D. (2015) Vybir mahovyh mas lanok peredatochnyh mehanizmiv na osnovi optymizacii' peredatochnoi' funkcii' [The choice of wing parts by weight of gear mechanisms based on optimizing the transfer function]. Matematychne modeliuvannia-Mathematical modeling, 2(33), 52-54 [in Ukrainian].

[5] Romaniuk O.D. (2015) Optymizacija mas zubchastyh kolis mehanichnoi' peredachi na etapi poperedn'ogo proektuvannja [Optimization of the masses of gears mechanical transmission during the preliminary design]. Matematychne modeliuvannia-Mathematical modeling, 2(35), 35-38 [in Ukrainian].

[6] Romaniuk O.D. (2018) Rozrobka matematy`chnoyi modeli obertal'ny`x vuzliv mexanichnoyi peredachi [Basic approaches to mass optimization of toothed wheels of mechanical transmission]. Matematychne modeliuvannia-Mathematical modeling, 1(38), 118-123 [in Ukrainian].

[7] Romaniuk O.D. (2019) [Development of rotary units mechanical transmission mathematical model]. Matematychne modeliuvannia -Mathematical modeling, 1(38), 118-123 [in English].

[8] Romaniuk O.D. (2020) [Optimization of masses of shafts and bearings of mechanical transfer]. Matematychne modeliuvannia-Mathematical modeling, 1(42), 41-47 [in Ukrainian]. 